\title{
Dificuldades e desafios na educação profissional técnica de nível médio em enfermagem
}

\author{
Isabella Cristina Moraes Campos \\ Instituto Federal Sudeste de Minas Gerais \\ (IF Sudeste MG - Campus São João del-Rei) \\ (isabella.campos@ifsudestemg.edu.br) \\ Isabel Cristina Adão Sciavon \\ Instituto Federal Sudeste de Minas Gerais \\ (IF Sudeste MG - Campus São João del-Rei) \\ (isabel.achiavon@ifsudestemg.edu.br) \\ Anadias Trajano Camargos \\ (Universidade Federal de Minas Gerais - UFMG) \\ anadiastcamargos@yahoo.com.br
}

Resumo: Os técnicos de enfermagem compõem a maior categoria profissional da área de saúde no Brasil e, portanto, é fundamental que sejam bem qualificados, de forma a promover uma melhor assistência à população. Esse estudo teve como objetivo levantar, nas publicações científicas brasileiras compreendidas no período entre 2001 e 2016, as dificuldades e os desafios da educação profissional técnica de nível médio em Enfermagem. A metodologia adotada foi a revisão integrativa da literatura com busca sistemática dos estudos realizada entre outubro e dezembro de 2016, nas bases de dados LILACS, SciELO, IBICT e USP. Após a análise das publicações, segundo os critérios de inclusão determinados, foram elegíveis 20 publicações. Os resultados foram apresentados através da estatística descritiva e em tabelas e quadros sinópticos. Observou-se a escassez de pesquisas sobre a temática nos últimos 15 anos (média de 1,33 estudos por ano) e uma concentração das produções no sudeste do país, especialmente no estado de São Paulo. Foi possível levantar as principais dificuldades vivenciadas nos cotidianos das escolas e os desafios para a melhoria da educação técnica em enfermagem. Os resultados dessa revisão trouxeram importantes subsídios para a reflexão acerca da educação profissionalizante em Enfermagem, na medida em que apontaram dificuldades.

Palavras-chave: Enfermagem; Educação Profissionalizante; Educação Técnica em Enfermagem.

\section{Difficulties and challenges in technical education in nursing}

Abstract: Nursing technicians make up the largest professional category in Brazil's health area and, therefore, it is essential that they are well qualified, in order to promote a better assistance to the population. The purpose of this study was to present, in Brazilian scientific publications comprised between 2001 and 2016, the difficulties and challenges of technical secondary education in nursing. The methodology adopted was the integrative review of the literature that seeks to systematize the studies carried out between October and December 2016, in the databases LILACS, SciELO, IBICT and USP. After the analysis of the publications, according to the specified inclusion criteria, 20 publications were eligible. The results were presented through descriptive statistics, in tables and synoptic tables. It was observed a lack of research on the subject in the last 15 years (average of 1.33 studies per year) and a concentration of productions in the southeast of the country, especially in the state of São Paulo. It was possible to raise the main difficulties experienced in the daily life of schools and the challenges for the improvement of technical education in nursing. The results of this review brought important contributions to the reflection on professional education in nursing, according as they pointed out difficulties.

Keywords: nursing; vocational education; education, nursing; associate. 


\section{INTRODUÇÃO}

Os técnicos de enfermagem surgiram no Brasil em 1966, quando foi criado o primeiro curso do país, na Escola Anna Nery, no Rio de Janeiro (KOBAYASHI, LEITE, 2004). No entanto, a regulamentação de seu exercício profissional apenas ocorreu em 1986, com a sanção da Lei no 7.498/86 (BRASIL, 1986), regulamentada pelo Decreto-Lei o 94.406/87 (BRASIL, 1987), que definiu as subcategorias que compõem a equipe de enfermagem - o enfermeiro (nível superior), o técnico de enfermagem (nível médio), o auxiliar de enfermagem (com ensino fundamental) e a parteira, e estabeleceu as competências privativas do enfermeiro e as atribuições de cada profissional (BRASIL, 1986). Reconheceu, ainda, o atendente de enfermagem, que atuava sem qualificação profissional, mas estipulou um prazo de dez anos para que a situação desses profissionais fosse resolvida (GÖTTEMS, ALVES, SENA, 2007).

Esta lacuna de 20 anos entre a criação do primeiro curso e a regulamentação da atuação do técnico de enfermagem pode ter sido uma das causas do subaproveitamento deste profissional, quer atuando como auxiliar de enfermagem, quer executando atividades pertinentes à sua própria função (KOBAYASHI; LEITE, 2004).

Desde a sua institucionalização, o ensino de Enfermagem vem passando por várias transformações influenciadas, muitas vezes, pelas condições sociopolíticas e culturais das várias épocas, que acarretaram a redefinição dos papeis atribuídos a esses trabalhadores (LEONART, MENDES, 2005; LIMA, CASSIANI, 2000). Tais mudanças tiveram como objetivo o desenvolvimento de competências nos profissionais de Enfermagem e o acompanhamento dos avanços técnico-científicos constantes na área de saúde (LIMA, CASSIANI, 2000).

Muitas dessas transformações partiram de iniciativas assumidas pelo Estado. Em 1963, foi criado o Programa para Formação de Auxiliares de Enfermagem (PROFAE) para as Regiões Norte, Nordeste e Centro-Oeste, que perdurou até o ano de 1973. Na década de 1980, merece destaque o Projeto Larga Escala, que, para a área de Enfermagem, constituiu-se em uma estratégia fundamental para a formação dos atendentes de Enfermagem, que, até então, atuavam sem qualificação profissional específica (GÖTTEMS, ALVES, SENA, 2007; GRYSCHEK, ALMEIDA, ANTUNES, MIYASHIRO, 2000; SANT'ANNA et al, 2007). 
No entanto, o marco mais importante do ensino técnico em enfermagem no país foi o Projeto de Profissionalização dos Trabalhadores da Área de Enfermagem (PROFAE), criado em 2000, pelo Ministério da Saúde. Suas metas principais foram qualificar os trabalhadores que atuavam sem habilitação para o exercício profissional e complementar a formação profissional do auxiliar para atuar como técnico de enfermagem. Pretendeu-se, portanto, formar recursos humanos na área da saúde e, consequentemente, melhorar a qualidade da assistência prestada nos serviços de saúde públicos e privados (BRASIL, 2001; COSTA et al., 2008; SANT`ANNA et al., 2007).

Por outro lado, o currículo mínimo dos cursos na área de Enfermagem foi mantido por cerca de 20 anos, tendo o enfoque no modelo biomédico, no hospital, na especialidade e no uso de tecnologias. Porém, este currículo foi desestimulado com a promulgação da Lei de Diretrizes e Bases da Educação Nacional (LDB), em 1996, da Resolução do Conselho Nacional de Educação (CNE)/Câmara de Educação Básica (CEB) no 04/99 e do Parecer CNE/CEB n 16/99 (BAGNATO, BASSINELLO, LACAZ, MISSIO, 2007).

A partir disso, as escolas se tornaram autônomas para organizarem seus currículos. Houve enfoque nas competências profissionais a serem desenvolvidas em função das demandas sociais, do mercado de trabalho, das peculiaridades locais e regionais e da capacidade institucional (SANT ANNA et al., 2007). A competência pode ser compreendida como o conjunto de conhecimentos, habilidades e atitudes de experiências anteriores mobilizado pelo aluno na busca por resolução de situações-problema (DIAS et al., 2013).

Assim, pretendia-se tornar os profissionais agentes multiplicadores do conceito ampliado de saúde que também se encontrava (e ainda se encontra) em pleno processo de reformulação, indo além do modelo biomédico de cura da doença para atender às demandas de saúde da população. Esse novo conceito de saúde foi debatido pelo movimento da Reforma Sanitária, que culminou com a institucionalização do Sistema Único de Saúde (SUS), através das Leis nํ 8.080/90 e no 8.142/90. Também foi incentivada a articulação das escolas com os serviços de saúde e a incorporação de novas metodologias de ensino (SANT ANNA et al., 2007).

Atualmente, os técnicos de enfermagem predominam no mercado de trabalho na área de saúde no Brasil, cuidando de pessoas sadias ou doentes, em todo o ciclo 
vital. Em levantamento realizado no portal do Conselho Federal de Enfermagem, no ano de 2017, há 1.944.313 profissionais de Enfermagem no Brasil, sendo que os técnicos totalizam 1.052.120 profissionais (54,11\%), denotando a representatividade dessa força de trabalho na saúde (CONSELHO FEDERAL DE ENFERMAGEM, 2017).

Ressalta-se que o campo de trabalho em Enfermagem está em expansão, sendo esta uma das poucas profissões cujo mercado de trabalho não está saturado. Dessa forma, torna-se fundamental que os técnicos de enfermagem tenham uma formação de qualidade que lhes permita o pleno exercício da profissão, de forma a contribuírem para a melhoria da qualidade do cuidado prestado e também uma atuação crítica que minimize para os usuários os riscos e iatrogenias decorrentes de sua prática.

No entanto, ainda são necessárias mudanças administrativas e pedagógicas, além de transformações nos padrões culturais das instituições e dos sujeitos nelas inseridos (LEONART, MENDES, 2005), bem como investimentos na avaliação dos cursos ofertados, na reestruturação dos currículos e no fortalecimento de parcerias (COSTA et al., 2008), como forma de assegurar uma educação profissionalizante de qualidade. Nesse sentido, é importante que se reconheça o papel social relevante dos centros formadores, não apenas como meros fornecedores de mão-de-obra para atendimento das necessidades do mercado de trabalho, mas também como centros difusores de conhecimento crítico, qualificado e emancipador.

O objetivo da pesquisa é analisar as publicações sobre a educação técnica em enfermagem, levantando as dificuldades e desafios encontrados pelos atores envolvidos neste processo formativo. A partir deste levantamento, será possível que os atores inseridos na educação em Enfermagem reflitam sobre sua prática docente, com vistas a promover a melhoria da formação dos técnicos de enfermagem.

\section{MATERIAIS E MÉTODOS}

\subsection{Revisão integrativa da literatura}

Este estudo adotou o delineamento metodológico de revisão integrativa da literatura, que permite a análise de pesquisas relevantes a respeito de uma área de 
estudo específica, gerando informações que darão suporte para a tomada de decisão e melhoria da prática (MENDES, SILVEIRA, GALVÃO, 2008). Além disso, proporciona a síntese do estado do conhecimento de um determinado assunto e aponta lacunas que precisam ser preenchidas com novos estudos. Com esta metodologia, pretende-se obter uma síntese de estudos científicos publicados que possibilitem retirar conclusões gerais acerca do tema investigado, que, no caso do estudo em tela, a educação profissional de nível médio em Enfermagem.

Para a realização elaboração da revisão integrativa, foram utilizadas as seis fases que compõem esse processo: estabelecimento da hipótese e objetivos da revisão integrativa; estabelecimento de critérios de inclusão e exclusão de artigos (seleção da amostra); definição das informações a serem extraídas dos artigos selecionados; análise dos resultados; discussão e apresentação dos resultados; e apresentação da revisão (URSI, GALVÃO, 2006). Mediante a revisão integrativa da literatura, buscou-se responder à seguinte questão norteadora: "Quais são as dificuldades e os desafios da educação profissional técnica de nível médio em enfermagem identificados em publicações sobre essa temática?"

Foi feita uma busca sistemática, no mês de outubro de 2016, da produção científica brasileira relacionada à educação profissional de nível técnico em enfermagem localizada na base de dados indexadas Literatura Latino-Americana em Ciências da Saúde (LILACS) e na biblioteca virtual Scientific Electronic Library Online (SciELO). Também foram consultadas a Biblioteca Digital Brasileira de Teses e Dissertações (BDTD) e a Biblioteca Digital de Teses e Dissertações da Universidade de São Paulo (USP).

Foram adotados os seguintes Descritores em Ciências da Saúde (DeCS) em quatro rodadas de combinações booleanas: na primeira busca foram definidos os descritores "Enfermagem" e "educação profissional'; na segunda busca, "Enfermagem" e "educação"; na terceira busca: "técnico de enfermagem"; e na quarta busca: "Enfermagem" e "educação profissionalizante". Estes descritores foram pesquisados nas bases de dados indexadas e nas listas de palavras-chave dos artigos que iam sendo selecionados. Além das estratégias de busca supracitadas, foi utilizada a busca reversa. Dessa forma, foram analisadas as referências de cada documento da amostra e, aquelas que atenderam aos critérios de inclusão determinados, também foram inseridas na amostra desta pesquisa. 


\subsection{Critérios de inclusão e exclusão}

Foram analisadas as publicações que atenderam aos critérios de inclusão a seguir: pertencer a alguma das bases de dados ou bibliotecas pesquisadas, ser um artigo, dissertação ou tese, ter como um dos autores um enfermeiro(a), estar disponível em texto completo, ser uma publicação brasileira, estar escrito em português, inglês ou espanhol e ter como assunto principal a educação profissional técnica de nível médio em Enfermagem. Também foram incluídos documentos tanto com abordagem quantitativa ou qualitativa, publicados a partir de 2001, pois, tendo em conta o número reduzido de publicações sobre o tema, optou-se por ampliar o horizonte temporal para o desenvolvimento da pesquisa. Foram excluídas, produções duplicadas, cartas, opiniões, manuais, cadernos, relatórios, pesquisas acerca da graduação em Enfermagem e outras produções não relacionadas ao escopo do estudo.

\subsection{Coleta e análise de dados}

Foi elaborado um instrumento de coleta de dados (Anexo1) próprio construído a partir das variáveis do estudo selecionadas previamente com o objetivo facilitar o processo de coleta e análise dos dados, sendo preenchido um instrumento para cada publicação.

Para a coleta e análise de dados, foram selecionadas as seguintes variáveis (GANONG, 1987; SOUZA, SILVA, CARVALHO, 2010):

1) Dados de identificação da publicação: título da publicação, título do periódico, base indexada, ano de publicação, tipo de publicação e idioma;

2) Dados de identificação do(s) autor(es) da publicação: nome, instituição, profissão, qualificação e área de atuação;

3) Dados do local do estudo: nome e localização;

4) Metodologia do estudo: objetivo, tipo de delineamento, população e amostra, resultados e discussão;

5) Principais resultados.

Para a análise descritiva das publicações, cada instrumento foi avaliado separadamente e foram construídos quadros sinópticos, com o emprego posterior da estatística descritiva para a caracterização da amostra, com cálculo de percentagem 
para a descrição das variáveis selecionadas para esta pesquisa. A leitura de cada publicação permitiu que fossem levantadas as dificuldades e desafios presentes na educação técnica em nível médio em enfermagem.

\subsection{População-alvo e amostra}

$\mathrm{Na}$ Tabela 1, estão relacionadas apenas as buscas que apresentaram algum resultado, bem como sua respectiva população-alvo - estudos localizados em cada busca realizada - e amostra - as publicações incluídas nesta revisão. Na contagem da amostra, foram excluídas as publicações que se repetiram entre as bases de dados.

Tabela 1. Distribuição das publicações, segundo base de dados, estratégia de busca, população e amostra, 2016.

\begin{tabular}{|c|c|c|c|}
\hline Base de dados & Estratégia de Busca & População-alvo & Amostra \\
\hline LILACS & $\begin{array}{l}\text { "educação profissional" [título] and } \\
\text { "enfermagem" [título] }\end{array}$ & 38 & 04 \\
\hline USP & $\begin{array}{l}\text { "educação profissional" [título] and } \\
\text { "enfermagem" [título] }\end{array}$ & 04 & 03 \\
\hline SciELO & "educação" [título] and "enfermagem" [título] & 132 & 02 \\
\hline LILACS & "educação" [título] and "enfermagem" [título] & 333 & 02 \\
\hline LILACS & "técnico de enfermagem" [título] & 51 & 02 \\
\hline BDTD & "técnico de enfermagem" [título] & 40 & 02 \\
\hline LILACS & $\begin{array}{l}\text { "educação profissionalizante" [título] and } \\
\text { "enfermagem" [título] }\end{array}$ & 5 & 01 \\
\hline $\begin{array}{c}\text { BUSCA } \\
\text { REVERSA }\end{array}$ & - & - & 4 \\
\hline & Total & 603 & 20 \\
\hline
\end{tabular}

Fonte: Elaborado pelas autoras, 2016.

\section{RESULTADOS}

A pesquisa de revisão integrativa foi realizada com as 20 publicações brasileiras que atenderam aos critérios de inclusão e exclusão determinados. Quanto às variáveis relativas às publicações, a análise do tipo de publicação revelou que $14(70,0 \%)$ são artigos, cinco (25,0\%) são dissertações de mestrado e uma 
(5,0\%) tese de doutorado. Quanto à localização das publicações, 12 (60,0\%) foram localizadas na LILACS, três (15,0\%) na BDTD, três (15,0\%) na USP e dois $(10,0 \%)$ na SciELO, de acordo com a Tabela 2.

Tabela 2. Distribuição da amostra, segundo as bases de dados indexadas, 2016.

\begin{tabular}{|ccc|}
\hline Base de dados & $\mathbf{N}$ & $\%$ \\
\hline LILACS & 12 & 60,0 \\
\hline USP & 3 & 15,0 \\
\hline IBICT & 3 & 15,0 \\
\hline SCIELO & 2 & 10,0 \\
\hline TOTAL & $\mathbf{2 0}$ & $\mathbf{1 0 0}$ \\
\hline
\end{tabular}

Fonte: Elaborado pelas autoras, 2016.

Dentre os 14 artigos, 12 (85,7\%) foram publicados em periódico da área de Enfermagem e dois (14,3\%) em periódicos de áreas afins. Todas as publicações (100\%) estavam redigidas em português. Quanto ao ano de publicação, 2007 foi o que apresentou o maior número de documentos publicados, com cinco $(25,0 \%)$ documentos; o ano de 2006 apresentou três (15,0\%) publicações; os anos de 2004, 2005 e 2008 tiveram duas (10,0\%) publicações cada e os anos de 2002, 2003, 2009, 2011, 2013 e 2015 tiveram uma (5,0\%) publicação cada.

Em relação às variáveis relativas aos autores, no total, as 20 publicações tiveram 63 autores. Deste total, 53 (84,1\%) eram enfermeiros, (10,2\%) não tiveram a sua profissão especificada e cinco (7,9\%) exerciam outras profissões, como psicólogo, estatístico, advogado e pedagogo. Quanto à qualificação dos autores, 23 $(36,5 \%)$ eram mestres, $21(33,3 \%)$ doutores, $13(20,6 \%)$ foram qualificados como mestrandos e doutorandos, quatro (6,3\%) eram especialistas, um (1,5\%) era graduado e um era pós-doutor (1,5\%). Quanto à área de atuação e à instituição dos autores, 33 (52,4\%) atuam em universidades, 19 (30,2\%) atuam diretamente em escolas técnicas de Enfermagem, e 11 (17,4\%) não tiveram a sua área de atuação especificada.

Quanto às variáveis relacionados ao local, 16 (80,0\%) estudos foram realizados em escolas técnicas e quatro (20,0\%) foram pesquisas de revisão e, portanto, não tiveram o local do estudo especificado. Quanto ao local de realização dos 20 estudos, sete estudos (35,0\%) foram realizados em São Paulo, três (15,0\%) em Minas Gerais, dois (10,0\%) no Ceará e os estados de Rio de Janeiro, Rio Grande do Sul, Rio Grande do Norte e Paraná tiveram um (5,0\%) estudo cada. 
As variáveis relacionadas à metodologia dos estudos evidenciaram que 16 $(80,0 \%)$ foram pesquisas com abordagem qualitativa, que utilizaram observações, questionários e entrevistas para a coleta de dados; e quatro $(20,0 \%)$ foram estudos de revisão de literatura. Quanto à amostra das 16 pesquisas, nove (56,3\%) foram realizadas apenas com estudantes, três $(18,8 \%)$ apenas com professores, duas $(12,5 \%)$ pesquisas apontaram que escolas técnicas compuseram a amostra, uma $(6,2 \%)$ com estudantes e professores, uma (6,2\%) com estudantes, professores, profissionais e usuários. Os autores, metodologias e principais achados apontados nas publicações estão apresentados a seguir na Tabela 3.

Tabela 3. Caracterização das publicações da amostra por autores, metodologia e principais resultados, 2016.

\begin{tabular}{|c|c|c|}
\hline $\begin{array}{l}\text { Autor(es) e } \\
\text { Ano }\end{array}$ & Metodologia & Principais resultados \\
\hline $\begin{array}{l}\text { Frias e } \\
\text { Takahashi } \\
(2002)\end{array}$ & $\begin{array}{l}\text { Pesquisa de } \quad \text { abordagem } \\
\text { qualitativa com } 14 \text { alunos de um } \\
\text { curso particular }\end{array}$ & $\begin{array}{l}\text { A análise da avaliação foi pautada em um conjunto de } \\
\text { significados que convergem para as categorias } \\
\text { ensino-aprendizagem, fatores emocionais e papel do } \\
\text { professor }\end{array}$ \\
\hline $\begin{array}{l}\text { Silva } \\
(2003)\end{array}$ & $\begin{array}{l}\text { Estudo exploratório-descritivo, } \\
\text { de abordagem qualitativa com } \\
\text { egressos }\end{array}$ & $\begin{array}{l}\text { Houve mudanças no saber-aprender, saber-fazer e } \\
\text { do saber-ser da qualificação do técnico de } \\
\text { enfermagem }\end{array}$ \\
\hline Ebisui (2004) & $\begin{array}{l}\text { Pesquisa qualitativa, descritiva e } \\
\text { exploratória com } 40 \text { professores }\end{array}$ & $\begin{array}{l}\text { O enfermeiro professor é comprometido com seu } \\
\text { papel, mas há algumas lacunas em relação ao seu } \\
\text { preparo pedagógico }\end{array}$ \\
\hline $\begin{array}{l}\text { Kobayashi e } \\
\text { Leite (2004) }\end{array}$ & $\begin{array}{lr}\text { Pesquisa } & \text { exploratória } \\
\text { documental } & \text { realizada em } 26 \\
\text { escolas } & \end{array}$ & $\begin{array}{l}\text { As competências gerais e específicas são } \\
\text { relacionadas a saber fazer, aprender a conhecer e a } \\
\text { saber ser }\end{array}$ \\
\hline $\begin{array}{l}\text { Leonart e } \\
\text { Mendes (2005) }\end{array}$ & $\begin{array}{l}\text { Estudo de caso em uma escola, } \\
\text { realizado com oito docentes, } \\
\text { coordenadora e r diretora } \\
\text { pedagógica e } 17 \text { alunos }\end{array}$ & $\begin{array}{l}\text { Há deficiência da formação de profissionais técnicos } \\
\text { em enfermagem competentes e habilitados ao } \\
\text { cuidado da população idosa }\end{array}$ \\
\hline Santos (2005) & $\begin{array}{l}\text { Estudo qualitativo com } \\
\text { abordagem participativa com } 12 \\
\text { professores e } 35 \text { alunos }\end{array}$ & $\begin{array}{l}\text { Foi apontado o uso excessivo de retroprojetor nas } \\
\text { aulas expositivas e os alunos se mostraram } \\
\text { desinteressados e desmotivados }\end{array}$ \\
\hline $\begin{array}{l}\text { Okane e } \\
\text { Takahashi } \\
(2006)\end{array}$ & $\begin{array}{l}\text { Estudo exploratório-descritivo, } \\
\text { com abordagem qualitativa, com } \\
14 \text { alunos }\end{array}$ & $\begin{array}{l}\text { O estudo dirigido permite desenvolver temas de } \\
\text { interesse do aluno, estimular o prazer em estudar e } \\
\text { incentivar o aluno a ser o sujeito de seu aprendizado }\end{array}$ \\
\hline $\begin{array}{l}\text { Stutz eJansen } \\
\qquad(2006)\end{array}$ & 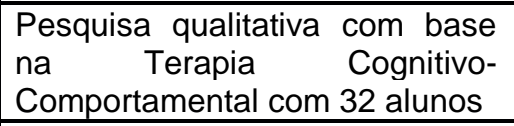 & $\begin{array}{l}\text { Os alunos relataram que as maiores dificuldades } \\
\text { referiam-se ao relacionamento interpessoal e } \\
\text { comunicação }\end{array}$ \\
\hline Zocche (2006) & 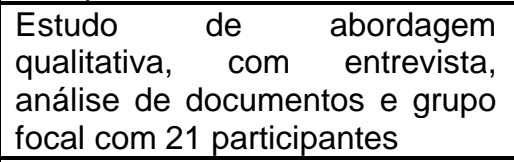 & $\begin{array}{l}\text { Tanto a formação quanto a avaliação da } \\
\text { aprendizagem estavam pautadas na prescrição } \\
\text { médica, nas rotinas de enfermagem e na história } \\
\text { natural da doença, mas não no cuidado humano }\end{array}$ \\
\hline $\begin{array}{l}\text { Appolinário } \\
\text { (2007) }\end{array}$ & 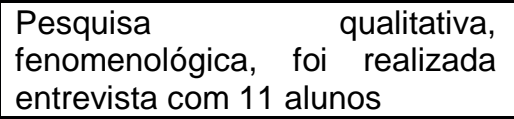 & $\begin{array}{l}\text { É preciso ensinar além dos procedimentos técnicos, } \\
\text { educando para o cuidado humanizado }\end{array}$ \\
\hline $\begin{array}{l}\text { Bagnato et al. } \\
\quad(2007)\end{array}$ & $\begin{array}{l}\text { Revisão teórica das políticas do } \\
\text { ensino profissionalizante e em } \\
\text { enfermagem brasileiras }\end{array}$ & $\begin{array}{l}\text { As legislações deveriam ser debatidas pelas } \\
\text { entidades de classe e envolvidos nos espaços de } \\
\text { educação e saúde }\end{array}$ \\
\hline $\begin{array}{l}\text { Ferreira et } \\
\text { al.(2007) }\end{array}$ & $\begin{array}{l}\text { Pesquisa qualitativa, com grupo } \\
\text { focal, realizada com } 90 \text { alunos }\end{array}$ & $\begin{array}{l}\text { Há demanda reprimida de trabalhadores da } \\
\text { enfermagem que necessitam de qualificação e a } \\
\text { problematização pode ser empregada em cursos } \\
\text { técnicos de enfermagem }\end{array}$ \\
\hline
\end{tabular}




\begin{tabular}{|c|c|c|}
\hline $\begin{array}{l}\text { Göttems, Alves } \\
\text { e Sena (2007) }\end{array}$ & $\begin{array}{l}\text { Revisão teórica sobre trajetória } \\
\text { da profissionalização dos } \\
\text { trabalhadores de nível médio da } \\
\text { enfermagem }\end{array}$ & $\begin{array}{l}\text { A educação profissional de nível técnico na } \\
\text { enfermagem produziu acumulação intelectual e } \\
\text { conceitual, e o PROFAE enfatizou o problema da } \\
\text { qualificação profissional da enfermagem }\end{array}$ \\
\hline $\begin{array}{l}\text { Padovani } \\
\text { (2007) }\end{array}$ & $\begin{array}{l}\text { Estudo descritivo-exploratório, } \\
\text { de abordagem qualitativa com } \\
\text { cinco professores }\end{array}$ & $\begin{array}{l}\text { Os docentes precisam atualizar seus conhecimentos, } \\
\text { além de repensar sua prática docente, baseando-a } \\
\text { práxis }\end{array}$ \\
\hline $\begin{array}{l}\text { Sant Anna et } \\
\text { al. (2007) }\end{array}$ & $\begin{array}{l}\text { Revisão teórica sobre as } \\
\text { principais mudanças ocorridas } \\
\text { na educação profissional técnica } \\
\text { de nível médio }\end{array}$ & $\begin{array}{l}\text { É preciso reconstruir novos planos de curso para } \\
\text { formar profissionais com competências básicas, com } \\
\text { novo olhar sobre a prática de saúde, com base no } \\
\text { princípio da integralidade e humanização da } \\
\text { assistência e no compromisso com a promoção da } \\
\text { saúde em todos os níveis de atenção }\end{array}$ \\
\hline $\begin{array}{l}\text { Costa et al. } \\
\qquad(2008)\end{array}$ & $\begin{array}{l}\text { Pesquisa qualitativa com } 10 \\
\text { supervisores de um curso do } \\
\text { PROFAE }\end{array}$ & $\begin{array}{l}\text { As dificuldades apontadas foram logística do curso, } \\
\text { pouco apoio da gestão municipal e limitação dos } \\
\text { campos de estágio }\end{array}$ \\
\hline $\begin{array}{l}\text { Costa et } \\
\text { al.(2009) }\end{array}$ & $\begin{array}{l}\text { Estudo descritivo-exploratório } \\
\text { com } 21 \text { egressos de um curso } \\
\text { do PROFAE }\end{array}$ & $\begin{array}{l}\text { As dificuldades apresentadas foram limitação do } \\
\text { campo de estágio, duração do curso e gerenciamento } \\
\text { de ajuda de custo }\end{array}$ \\
\hline $\begin{array}{l}\text { Lima e } \\
\text { Appolinário } \\
\text { (2011) }\end{array}$ & $\begin{array}{l}\text { Pesquisa exploratória com } \\
\text { revisão bibliográfica de artigos e } \\
\text { livros }\end{array}$ & $\begin{array}{l}\text { As dificuldades apontadas pelos docentes foram falta } \\
\text { de conhecimento do processo de ensinar, de material } \\
\text { didático e infraestrutura, baixos salários, dentre } \\
\text { outras. Em relação aos alunos, foram angústia e } \\
\text { ansiedade no início do estágio e dificuldades de } \\
\text { relacionamento com o outro durante o estágio }\end{array}$ \\
\hline $\begin{array}{l}\text { Dias et } \\
\text { al.(2013) }\end{array}$ & $\begin{array}{l}\text { Revisão integrativa da literatura } \\
\text { sobre o ensino por } \\
\text { competências em enfermagem }\end{array}$ & $\begin{array}{l}\text { O ensino por competências é pouco utilizado e as } \\
\text { competências desenvolvidas foram das seguintes } \\
\text { famílias: organizar e dirigir situações de } \\
\text { aprendizagem; administrar a progressão das } \\
\text { aprendizagens e administrar sua própria formação } \\
\text { contínua }\end{array}$ \\
\hline $\begin{array}{l}\text { Góes et } \\
\text { al.(2015) }\end{array}$ & $\begin{array}{l}\text { Estudo qualitativo, descritivo } \\
\text { exploratório com } 119 \text { alunos, } \\
\text { três professores e um } \\
\text { coordenador do curso técnico }\end{array}$ & $\begin{array}{l}\text { Os alunos têm dificuldades em conteúdos como } \\
\text { português e matemática, e em disciplinas } \\
\text { introdutórias do curso o que pode interferir na } \\
\text { aprendizagem de conteúdos específicos }\end{array}$ \\
\hline
\end{tabular}

Fonte: Elaborado pelas autoras, 2016.

\section{DISCUSSÃO}

Os resultados dos estudos analisados trouxeram importantes subsídios para a reflexão acerca da educação profissionalizante em Enfermagem, na medida em que apontaram dificuldades vivenciadas nos cotidianos das escolas. Em relação aos professores, o estudo de Padovani (2007) apontou que apenas 40\% tinham licenciatura, $80 \%$ também trabalhavam na assistência e havia número reduzido de professores em relação ao total de alunos e turmas. Todos desconheciam ou apenas conheciam parcialmente o Projeto Político Pedagógico (PPP) do curso. O PPP, portanto, não era utilizado para melhoria da qualidade das aulas, para a renovação da prática pedagógica e para o conhecimento dos interesses sociais e pedagógicos da instituição. 
Lima e Appolinário (2011) apontaram que os educadores pesquisados não tinham conhecimento do processo de ensinar e recebiam baixos salários, o que os levavam a buscar um trabalho adicional. Essa situação gerava o acúmulo de atividades e a falta de tempo para se preparar e dedicar mais à docência. A falta de formação pedagógica de professores também foi identificada no estudo realizado por Ebisui (2004). Cabe ressaltar, entretanto, que a LDB n 9394/96 preconizou a obrigatoriedade do curso de licenciatura ou da capacitação pedagógica para os professores que atuam na educação profissional.

Embora três estudos tenham abordado a importância do estágio curricular obrigatório como momento crucial de prática dos conhecimentos adquiridos, Appolinário (2007) mostrou que o ensino, durante o estágio no Centro de Terapia Intensiva, era essencialmente técnico e baseado no modelo biologicista, com o predomínio da realização de procedimentos. Não era prestado um cuidado integral aos pacientes, o que levou a autora a concluir que a prática educativa deveria também abordar a humanização da assistência de Enfermagem, além das questões subjetivas e familiares dos pacientes (APPOLINÁRIO, 2007).

Outra dificuldade apontada foi que o momento do estágio gerava angústia e ansiedade nos estudantes, principalmente para aqueles que nunca tiveram contato prévio com um hospital. Deparavam-se com a dificuldade em lidar com as diferenças entre a técnica aprendida na escola e a técnica utilizada por alguns funcionários, o que gerava conflitos nas decisões referentes à sua atuação profissional. Além disso, tinham dificuldade de relacionamento com os funcionários da instituição e com os próprios pacientes (LIMA, APPOLINÁRIO, 2011). Stutz e Jansen (2006) identificaram uma lacuna importante no aprendizado dos alunos, a qual se evidenciou por uma dificuldade de relacionamento e comunicação, o que pode interferir de forma negativa nos resultados obtidos pela equipe. Observou-se a necessidade da formação de relações interpessoais saudáveis e da criação de um ambiente propício para o esclarecimento das dúvidas e elaboração das vivências dos discentes (STUTZ, JANSEN, 2006).

Quanto à metodologia adotada durante as aulas teóricas, a aula expositiva predominou e o uso do retroprojetor foi apontado como excessivo. Tanto professores quanto os alunos relataram desmotivação e desinteresse durante as aulas, com maior necessidade de motivação para o sucesso do processo de ensinoaprendizagem (SANTOS, 2005). Por outro lado, o estudo dirigido foi avaliado como 
uma "boa" estratégia de ensino por $86 \%$ dos estudantes pesquisados, sendo apontado como uma alternativa à metodologia tradicional e verticalizada de ensino (OKANE, TAKAHASHI, 2006).

Outra metodologia de ensino inovadora citada foi a problematização, apontada em três estudos (COSTA et al., 2009; COSTA et al., 2008; FERREIRA et al., 2007). Segundo os autores, a problematização motivou o processo de ensinoaprendizagem por ser uma metodologia ativa, além relacionar teoria e prática e aproximar o aluno da realidade concreta. Além disso, propiciou uma visão renovada do docente sobre $\mathrm{o}$ ato de ensinar e de aprender, superando a metodologia tradicional de ensino. Também foram citadas como metodologias de ensino inovadoras pesquisas, estudos em grupo, debates e trocas de experiências (FRIAS, TAKAHASHI, 2002). Todas foram consideradas como oportunidades dos educandos serem sujeitos ativos do processo de ensino-aprendizagem e responsáveis pelo seu conhecimento.

No estudo conduzido por Góes et al. (2015) foi demonstrado que os alunos de um curso tinham dificuldades em conteúdos não relacionados à Enfermagem, como português e matemática, e também em disciplinas introdutórias do curso, como anatomia e farmacologia, o que poderia interferir na aprendizagem de conteúdos específicos acerca da Enfermagem. Outro aspecto observado foi que nenhum participante do estudo discorreu sobre aprendizagem de conteúdos relacionados à prevenção, promoção e educação em saúde. Além disso, os alunos manifestaram que vídeo-aulas, jogos e e-books seriam ferramentas de ensino atrativas (GÓES et al., 2015). Dessa forma, torna-se urgente a busca por ferramentas de ensino que proporcionem a interdisciplinaridade de acordo com essa realidade e que forneçam subsídios para a capacitação do professor para atuar na docência em educação profissional técnica em Enfermagem.

Quanto às formas de avaliar o aprendizado dos estudantes, observou-se que, ao fazê-la, o professor não deve apenas classificar o aluno dentro de padrões predeterminados e dar o veredicto final, sem antes ter a certeza de que todas as possibilidades de aprendizado foram esgotadas (SILVA, 2003). A avaliação deveria ser adotada como um instrumento para se perceber o desenvolvimento do saber do educando e as necessidades de reorientação do processo educacional. A avaliação não pode ser pontual e fragmentada. Não deve estar atrelada a metas finais, rotinas e realização de técnicas, sem a compreensão do cuidado humano. Assim, o 
processo avaliativo deve ser uma "teia" entre o desempenho cognitivo e o laboral, avaliando as competências adquiridas pelos estudantes (ZOCCHE, 2006).

As competências desenvolvidas nos cursos técnicos em enfermagem foram o tema central de três pesquisas. No estudo desenvolvido por Kobayashie Leite (2004), observou-se que as competências administrativas mais desenvolvidas nos técnicos de enfermagem estavam relacionadas ao "saber fazer" e "aprender a conhecer", em detrimento do "saber ser". Os autores relataram a necessidade do desenvolvimento do "saber ser" dos técnicos de enfermagem, que, essencialmente, assistem a saúde dos seres humanos (KOBAYASHI, LEITE, 2004). Dessa forma, os profissionais precisam ser capacitados para transpor o trabalho meramente operacional, passando a conhecer integralmente o processo de trabalho.

Já o trabalho de Leonart e Mendes (2005) identificou que há uma deficiência na formação de profissionais técnicos de enfermagem competentes e habilitados ao cuidado da população idosa. Isso pode ser apontado como uma desatualização dos currículos, visto que um dos desafios da atualidade mundial e brasileira é o acelerado envelhecimento populacional, que passou a exigir uma adequação dos papeis e das ações dos profissionais de saúde para atender os idosos (LEONART, MENDES, 2005).

Dias e colaboradores (2013) verificaram que o emprego do ensino por competências pelos cursos técnicos em enfermagem ainda é tímido e que as competências mais desenvolvidas foram: "1. Organizar e dirigir situações de aprendizagem" e “10. Administrar sua própria formação contínua”, embora a utilização do ensino por competências na educação profissional tenha sido prevista na LDB em 1996 (DIAS et al., 2013). Ademais, a educação ainda está baseada somente na prática, reforçando a necessidade de mudanças, pois há um distanciamento das rotinas pedagógicas e didáticas, que em nada contribuem para construção de competências.

Três pesquisas apontaram os desafios da educação profissional técnica de nível médio em Enfermagem. O seu desafio central é a formação de profissionais autônomos, críticos e competentes para atuarem na área da saúde que se encontra em constante transformação, tanto no que tange ao avanço tecnológico quanto à concepção de atenção à saúde voltada aos princípios do SUS (SANT'ANNA et al., 2008). 
Ademais, as escolas devem se ocupar com a melhoria dos processos formativos, a partir da capacitação constante do corpo docente, da reformulação dos seus projetos pedagógicos, da construção de novos conhecimentos sobre o trabalho em saúde e da elaboração de materiais didáticos. Além disso, foi apontada a necessidade da articulação entre educação e trabalho, mediante ações conjuntas entre a escola, os serviços de saúde, a gestão e as instâncias de controle social, com a participação dos profissionais já inseridos no mercado de trabalho (GÖTTEMS, ALVES, SENA,2007).

Finalmente, foi ressaltada a necessidade de um amplo debate entre as entidades de classe da área de Enfermagem, com a participação dos profissionais do ensino técnico e da área de saúde. Esta ação conjunta seria importante para a elaboração de um projeto de formação voltado para as necessidades de saúde da população, contemplando as múltiplas dimensões do conhecimento, como os aspectos técnico-científicos, éticos, políticos, sociais e culturais (BAGNATO et al., 2007).

\section{CONCLUSÕES}

Esta revisão integrativa da literatura evidenciou que, no período entre 2001 a 2016, houve poucas publicações nacionais a respeito da educação profissional técnica de nível médio em enfermagem, tendo em vista que, após uma ampla busca sistemática, apenas 20 publicações foram elegíveis para esta revisão, ou seja, uma média de 1,33 estudos por ano. Esta é uma constatação preocupante, visto que há inúmeros cursos técnicos em enfermagem no país e, portanto, torna-se essencial uma reflexão constante sobre o tema. Um levantamento no portal do Conselho Regional de Enfermagem de Minas Gerais permitiu verificar que, apenas no estado, existiam, até o ano de 2016, 122 cursos de formação de técnicos de enfermagem cadastrados. Além de escassas, essas pesquisas estão concentradas na região sudeste do país, especialmente no estado de São Paulo.

Além disso, a análise das publicações permitiu evidenciar os desafios ainda existentes na educação profissional de nível médio em enfermagem e que podem afetar a sua qualidade, tais como desconhecimento do PPP, ausência de formação pedagógica específica, estágio obrigatório técnico e calcado no modelo biomédico, 
ausência de conteúdos sobre humanização da assistência e relacionamento interpessoal, criação de vínculos para relato de experiências em campo prático, aulas muito expositivas, necessidade de conteúdos voltados ao cuidado da população idosa, dentre outros. Assim, acredita-se que o debate sobre a temática deva ser ampliado e subsidiado por mais pesquisas. Adicionalmente, torna-se fundamental que os professores repensem a sua prática pedagógica, tornando-a uma práxis transformadora do educando e da sociedade. Consequentemente, serão formados técnicos de enfermagem que, além de possuírem as competências básicas exigidas pelo mercado de trabalho, serão capazes de prestar uma assistência integral e humanizada à população.

\section{REFERÊNCIAS}

APPOLINÁRIO, R. S. Educação profissional: vivência do educando no cuidado ao paciente crítico. 2007. Dissertação (Mestrado) - Escola de Enfermagem de Ribeirão Preto, Universidade de São Paulo, Ribeirão Preto, SP, Brasil.

BAGNATO, M. H. S.; BASSINELLO, G. A. H.; LACAZ, C. P. C.; MISSIO, L. Ensino médio e educação profissionalizante em enfermagem: algumas reflexões. Rev. Esc. Enferm. USP, v. 41, n.2, p. 279-286, 2007.

BRASIL. Lei no 7.498/86, 25 de junho de 1986. Dispõe sobre a regulamentação do exercício da enfermagem. Brasília, DF, jun 1986.

Decreto-Lei no 94.406, 8 de junho de 1987. Regulamenta a Lei no 7.498, de 25 de junho de 1986, que dispõe sobre o exercício da Enfermagem, e dá outras providências. Brasília, DF, jun 1987.

Ministério da Saúde; Secretaria de Gestão de Investimentos em Saúde. Edital do projeto de profissionalização dos trabalhadores da área de enfermagem: PROFAE: Estado do Ceará. Brasília (DF), Brasil.2001.

CONSELHO FEDERAL DE ENFERMAGEM. Enfermagem em Números. [Internet]. Brasília, 2017. Disponível em:<http://www.cofen.gov.br/enfermagem-em-numeros >. Acesso em 19 jul. 2017.

COSTA, C.C.C.; BEZERRA FILHO, J.G.; MACHADO, M.M.T.; MACHADO, M.F.A.S.; JORGE, A.C.; FURTADO, A.A.A. et al. Curso técnico de Enfermagem do PROFAE Ceará: a voz dos supervisores. Texto Contexto Enferm., v.17, n. 4, p.705-713, 2008.

COSTA, C.C.C.; BEZERRA FILHO, J.G.; MACHADO, M.M.T.; MACHADO, M.F.A. S.; JORGE, A. C.; CASTRO, T.M.S. Curso Técnico de Enfermagem do PROFAE - Ceará: uma análise sob a óptica dos egressos. Rev. Esc. Enferm. USP, v. 43, n. 3, p. 520 527, 2009. 
DIAS, R.A.; SCHIAVON, I.C.A.; OLIVEIRA, E.C.; CAMPOS, I.C.M. O ensino por competências na educação do profissional técnico de nível médio em Enfermagem: uma revisão integrativa. Rev. Enferm. Cent.-Oeste Min, v. 3, n. 3, p. 883-890, 2013.

EBISUI, C.T.N. A identidade profissional do enfermeiro professor do ensino técnico em enfermagem. 2004. Dissertação (Mestrado) -Escola de Enfermagem de Ribeirão Preto, Universidade de São Paulo, Ribeirão Preto, SP, Brasil.

FERREIRA, M.A.; OLIVEIRA, B.G.R.B.; PORTO, I.S.; ANHORN, C.G.; CASTRO, J.B.A. O significado do PROFAE segundo os alunos: contribuição para a construção de uma política pública de formação profissional em saúde. Texto Contexto Enferm.,v. 16, n. 3, p. 445-452, 2007.

FRIAS, M.A.E.; TAKAHASHI, R.T. Avaliação do processo ensino-aprendizagem: seu significado para o aluno de ensino médio de enfermagem. Rev. Esc. Enferm. USP, v. 36, n. 2, p. 156-163, 2002.

GANONG, L.H. Integrative reviews of nursing research. Research in Nursing \& Health, v. 10, n. 1, p. 1-11, 1987.

GÖTTEMS, L. B. D.; ALVES, E.D.; SENA, R.R. A enfermagem brasileira e a profissionalização de nível técnico: análise em retrospectiva. Rev. Latino-am. Enfermagem, v. 15, n. 5, p. 1033-1040, 2007.

GÓES, F.S.N.; CÔRREA, A.K.; CAMARGO, R.A.A.; HARA, C.Y.N. Necessidades de aprendizagem de alunos da Educação Profissional de Nível Técnico em Enfermagem. Rev Bras Enferm., v. 68, n. 1, p. 20-25, 2015.

GRYSCHEK, A.L.F.P.L.; ALMEIDA, A.H.; ANTUNES, M.N.; MIYASHIRO, S.Y. Projeto larga escala: uma proposta pedagógica atual. Rev. Esc. Enferm. USP, v.34, n. 2, p. 196201, 2000.

KOBAYASHI, R.M.; LEITE, M.M.J. Formação de competências administrativas do técnico de enfermagem. Rev. Latino-am. Enfermagem, v. 12, n. 2, p. 221-227, 2004.

LEONART, E.; MENDES, M.M.R. Formação gerontológica do técnico em enfermagem: uma abordagem cultural. Rev. Latino-am. Enfermagem, v. 13, n. 4 p. 538-546, 2005.

LIMA, E.C.; APPOLINÁRIO,R.S. A educação profissionalizante em enfermagem no Brasil: desafios e perspectivas. Rev. Enferm. UERJ, v. 19, n. 2, p. 311-316, 2011.

LIMA, M.A.C.; CASSIANI, S.H.D.B. Pensamento crítico: um enfoque na educação de enfermagem. Rev. Latino-am. Enfermagem, v. 8, n. 1, p. 23-30, 2000.

MENDES, K.D.S.; SILVEIRA, R.C.C.P.; GALVÃO, C.M. Revisão integrativa: método de pesquisa para a incorporação de evidências na saúde e na enfermagem. Texto Contexto Enferm., v. 17, n. 4, p. 758-764, 2008.

OKANE, E. S. H.; TAKAHASHI, R. T. O estudo dirigido como estratégia de ensino na educação profissional em enfermagem. Rev. Esc. Enferm. USP, v. 40, n. 2, p. 160169, 2006.

PADOVANI, O. A prática pedagógica na educação profissional técnica de nível médio em enfermagem: estudo em uma escola privada do interior de São Paulo. 2007. 
Dissertação (Mestrado) - Escola de Enfermagem de Ribeirão Preto, Universidade de São Paulo, Ribeirão Preto, SP, Brasil.

SANT'ANNA, S.R.; ENNES, L.D.; SOARES, L.H.S.; OLIVEIRA, S.R.; SANT'ANNA, L.S. A influência das políticas de educação e saúde nos currículos dos cursos de educação profissional técnica de nível médio em enfermagem. Trab. Educ. Saúde, v. 5, n. 3, p. 415-431, 2007.

SANTOS, L.H.P. Estratégias e avaliação no processo de ensino-aprendizagem e a postura do professor na educação profissional em enfermagem. 2005. Dissertação (Mestrado) -Escola de Enfermagem de Ribeirão Preto, Universidade de São Paulo, Ribeirão Preto, SP, Brasil.

SILVA, E.R. O cidadão técnico em enfermagem: analisando as mudanças na sua profissionalização. 2003. Dissertação (Mestrado) - Centro de Ciência da Saúde, Universidade Federal do Rio Grande do Norte, Natal, RN, Brasil.

SOUZA, M.T.; SILVA, M.D.; CARVALHO, R. Revisão integrativa: o que é e como fazer? Einstein, v. 8, n. 1, p. 102-106, 2010.

STUTZ, B. L.; JANSEN, A. C. Ensino técnico na área da saúde: os desafios do processo de aprendizagem. Revista Semestral da Associação Brasileira de Psicologia Escolar e Educacional, v. 10, n. 2, p. 211-221, 2006.

URSI, E.S., GALVÃO, C.M. Prevenção de lesões de pele no perioperatório: revisão integrativa da literatura. Rev Latino-am. Enferm., v. 14, n. 1, p. 124-131, 2006.

ZOCCHE, D.A.S. Teias da avaliação no ensino-aprendizagem em saúde: uma "análise da situação" da avaliação dos desempenhos cognitivo e laboral no ensino técnico em enfermagem. 2006. Dissertação (Mestrado) - Faculdade de Educação, Universidade Federal do Rio Grande do Sul, Porto Alegre, RS, Brasil. 
Dificuldades e desafios na educação profissional técnica de nível médio em enfermagem

ANEXO 1 - Instrumento de Coleta de Dados

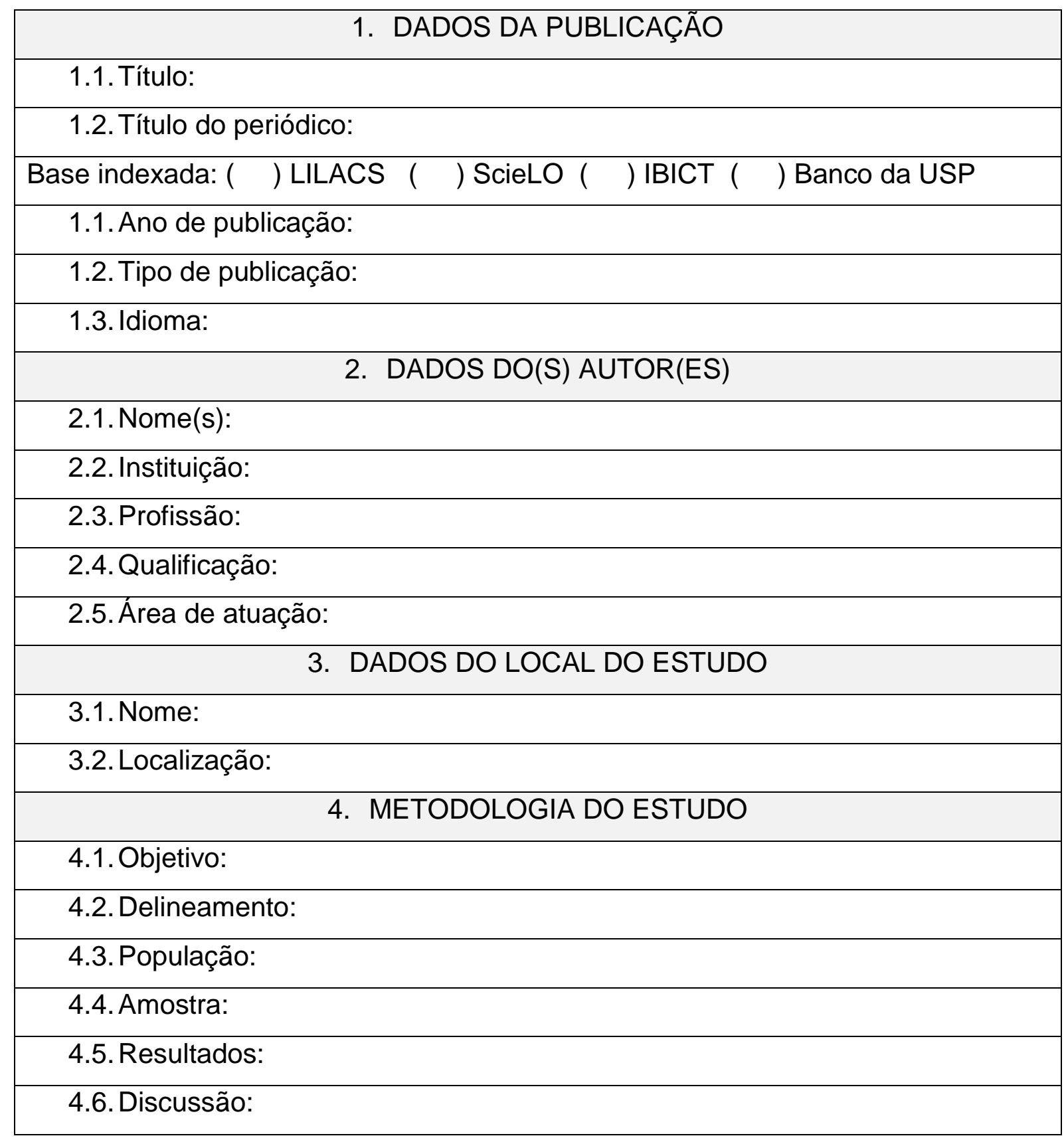

